\title{
CORRECTIONS
}

\section{Sequential bilateral femoral fractures}

In the online version of this Endgames case report by Seyed Ali Moeinoddini and colleagues (BMJ 2012;345:e7361, doi:10. 1136/bmj.e7361), the affiliations of the last two authors are reversed. Sarah Ruth Moore should be affiliated to East Cheshire NHS Trust, Macclesfield District General Hospital,

Macclesfield, UK and David James Moore should be affiliated to Sheffield Teaching Hospitals NHS Trust, Northern General Hospital, Sheffield, UK.

Cite this as: BMJ 2012;345:e8139

๑ BMJ Publishing Group Ltd 2012 